\title{
Pharmacologic characterization of the $\mathrm{Na}^{+}$ionophores in $\mathrm{L} 6$ myotubes
}

(tetrodotoxin/saxitoxin/veratridine/grayanotoxin/electrically excitable membrane)

\author{
ANTONIO SASTRE AND ThOMAS R. PODleski
}

Section of Neurobiology and Behavior, Cornell University, Ithaca, New York 14853

Communicated by Thomas Eisner, January 26, 1976

\begin{abstract}
We present a pharmacologic characterization of the $\mathrm{Na}^{+}$ionophores present in $\mathrm{L6}$ myotubes in vitro. Action potentials are abolished by replacement of the external $\mathrm{Na}^{+}$by Tris. The amplitude of the action potential is generally resistant to high concentrations of tetrodotoxin $\left(10^{-5}\right.$ $M)$ and saxitoxin $\left(10^{-6} \mathrm{M}\right)$, but the effect of these agents is highly variable. Veratridine $\left(10^{-4} \mathrm{M}\right)$ consistently induces, as a short-term effect, a marked prolongation of the falling phase of the action potential. As a long-term effect, veratridine consistently induces a $\mathrm{Na}^{+}$-dependent reduction in the resting potential of the cell. The effects of veratridine on the action potential are not antagonized by tetrodotoxin or saxitoxin. However, the effects of veratridine on the resting potential are strongly antagonized by tetrodotoxin $\left(10^{-5} \mathrm{M}\right)$ and fully inhibited by saxitoxin $\left(10^{-6} \mathrm{M}\right)$. Significantly, under conditions where saxitoxin has fully inhibited the effects of veratridine on the resting potential, the myotubes are capable of generating overshooting action potentials. In contrast to their sensitivity to veratridine, $\mathrm{L} 6$ myotubes are insensitive to $10^{-5} \mathrm{M} \alpha$-dihydro-grayanotoxin-II. These results are discussed in the contexts of developmental significance and current views about $\mathrm{Na}^{+}$ionophores.
\end{abstract}

The elucidation of the molecular events underlying the development of chemical and electrical excitability in embryonic systems remains one of the challenges of developmental cell biology. The complexity of most embryonic systems has prevented an analysis of the relevant variables in situ, although some striking results have been obtained (1).

The rat skeletal muscle line L6 isolated by Yaffe (2) provides a system in which the development of chemical and electrical excitability may be studied in vitro. L6 myoblasts are seldom electrically excitable (3-5); their response to acetylcholine is not characteristic of skeletal muscle (6). When myoblasts fuse to form multinucleated myotubes, the cells develop electrical excitability (3-5) and the cholinergic response becomes nicotinic (6-8).

The L6 myotubes share many characteristics of embryonic and denervated skeletal muscle: $(i)$ sensitivity to acetylcholine throughout the length of the fiber (7-10); (ii) action potentials (APs) are most readily elicited by anode-break excitation $(3-5,11)$; (iii) the APs are $\mathrm{Na}^{+}$-dependent but resistant to tetrodotoxin (TTX) $(3,4,12,13) ;$ (iv) the myotube membrane is electrogenically heterogeneous with membrane patches generating spontaneous APs, patches where APs are neither conducted nor can be elicited, and patches incapable of sustaining spontaneous activity but capable of responding to current stimuli with single APs; in L6 action potentials are generally not propagated (ref. 14; Sastre and Podleski, manuscript in preparation).

L6 myotubes can form functional synapses when innervated by rat spinal cord explants (15). Thus, L6 is a suitable

Abbreviations: AP, action potential; TTX, tetrodotoxin; STX, saxitoxin; $\alpha$-DH-GTX-II, $\alpha$-dihydro-grayanotoxin-II. model system for the study of changes in the properties of muscle fibers which take place upon innervation.

Here we report a further characterization of the voltagedependent, TTX-resistant $\mathrm{Na}^{+}$ionophore present in $\mathrm{L} 6 \mathrm{my}-$ otubes, with use of neurotoxins of known specificity for $\mathrm{Na}^{+}$ channels. We have examined the effects of two agents which block $\mathrm{Na}^{+}$ionophores, TTX (16) and saxitoxin (STX) (16), and two agents known to induce a large increase in the resting permeability of the electrically excitable membranes to $\mathrm{Na}^{+}$, veratridine $(17,18)$, and $\alpha$-dihydro-grayanotoxin-II $(\alpha$-DH-GTX-II) (19).

\section{MATERIALS AND METHODS}

L6 myoblasts (gift of Dr. D. Schubert, Salk Institute) were grown in Dulbecco's modified Eagle's medium supplemented with $10 \%$ fetal calf serum (Gibco) at $37^{\circ}$ in an atmosphere of $5 \% \mathrm{CO}_{2}, 95 \%$ air, and $100 \%$ humidity. Exponentially growing cells were subcultured with $0.25 \%$ Viokase (Gibco) and plated on Falcon or Corning tissue culture dishes at about $2 \times 10^{5}$ cells per $60 \mathrm{~mm}$ dish. Cells were routinely subcloned and selected for the ability to fuse extensively. Our observations have been made over a period of 8 months with use of various subclones and more than 405 cell generations. The parameters discussed here have remained stable and we believe them to be representative properties of L6. Observations were always made after extensive fusion had occurred (6-14 days after plating); the myotubes were frequently striated and sometimes contracted when depolarized. The myotubes used in this study are much younger than the ones reported on in our first report (4). By recloning the cells about every 6 weeks we have been able to maintain cells which fuse in 6-14 days. These cells fuse more extensively than the ones used previously. In most respects, the electrical responses of the myotubes in the two studies are similar.

Electrophysiological measurements were made at room temperature of $20-22^{\circ}$ in Tyrode's solution of the following composition (in mmol/liter): $\mathrm{NaCl}, 138 ; \mathrm{KCl}, 2.7 ; \mathrm{MgCl}_{2}$, $1.8 ; \mathrm{CaCl}_{2}, 1.8 ; \mathrm{NaH}_{2} \mathrm{PO}_{4}, 0.42$; glucose, 5.5 ; Hepes $(\mathrm{N}-2-$ hydroxyethylpiperazine- $N^{\prime}-2$ ethanesulfonic acid), 18. The $\mathrm{pH}$ was adjusted to 7.4. To minimize effects of evaporation we replaced the solution every $15-20 \mathrm{~min}$. Glass microelectrodes filled with $3 \mathrm{M} \mathrm{KCl}$ and having dc impedances of 20-70 $\mathrm{m} \Omega$ were used for intracellular recording. Electrodes were connected via capacity-neutralized preamplifiers (models M-4A and 701 from WP Instruments, Inc.) with bridge circuits for passing current and recording potential simultaneously. Due to the input impedance of these cells (1 $\mathrm{m} \Omega \leq \mathrm{R}_{\mathrm{I}} \leq 20 \mathrm{~m} \Omega$ ) currents $\geq 25 \mathrm{nA}$ were sometimes required for stimulating; in these cases the WP 701 in highcurrent injection mode was used. After publication of our 


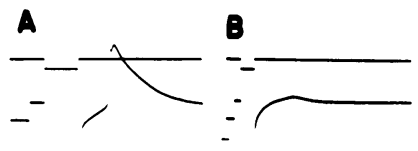

C

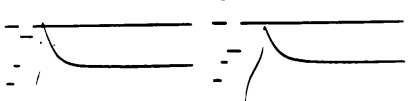

E

$\boldsymbol{F}$

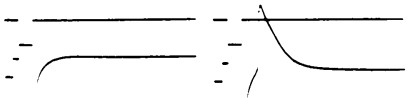

FIG. 1. Intracellular recording of action potentials in L6 myotubes. The upper trace represents zero potential and also monitors applied current. The lower trace measures membrane potential, starts with a calibration pulse, then follows a short segment of the resting potential before the current-induced hyperpolarization. The calibration pulse is $20 \mathrm{mV}$ in amplitude (or $25 \mathrm{nA}$ of current for the upper trace) and $20 \mathrm{msec}$ in duration. A-F were obtained from the same myotube. A, control Tyrode's; B, $10^{-6} \mathrm{M}$ STX; C, washout of STX with Tyrode's; D, $10^{-5} \mathrm{M}$ TTX; E, $\mathrm{Na}^{+}$-free $\mathrm{Ty}$ rode's; F, recovery in Tyrode's.

first report (4), we noted that in some cases the threshold of the myotube changed when TTX was present. In all cases reported here, we have stimulated the cells with the least amount of current that would elicit a maximal AP response. When changing solutions with electrode(s) in myotubes, the dish was perfused with $25-50 \mathrm{ml}$ of solution. The only data kept for analysis were obtained from cells where full reversal to the control response was obtained. The only exception was when treating cells with veratridine; only partial reversal was obtained after prolonged washes.

Chemicals were obtained from the following sources: TTX (purified by Sankyo, Japan) from Calbiochem; veratridine from K \& K Laboratories, Inc., $\alpha$-DH-GTX-II and saxitoxin were kind gifts of Drs. T. Narahashi and E. Schantz, respectively. All other chemicals were of the highest purity available. Saxitoxin was stored as an acidified stock solution. After about 6 months its potency was tested by bioassay (20); no significant degradation had occurred.

\section{RESULTS}

\section{Dependence of AP on $\mathrm{Na}^{+}$}

Consistent with previous observations (4), APs are invariably abolished when the $\mathrm{Na}^{+}$in the recording solution is replaced by equiosmolar Tris [tris(hydroxymethyl)aminomethane] (see Fig. 1E).

\section{Low sensitivity to TTX and STX}

We have reexamined the sensitivity of the cells to TTX, and we studied the effects of STX, a known powerful blocker of $\mathrm{Na}^{+}$-dependent APs (16).

Concentrations of TTX less than $10^{-6} \mathrm{M}$ (or STX $10^{-7} \mathrm{M}$ ) do not affect the threshold, amplitude, or duration of the AP. Sometimes these concentrations abolish spontaneous activity, but the fiber remains responsive to current stimuli (ref. 4; Land and Sastre, unpublished). Most of our work was done with $10^{-5} \mathrm{M}$ TTX or 1.0 to $1.6 \times 10^{-6} \mathrm{M} \mathrm{STX}$, the highest concentrations of these agents we have tested. For reference we note that APs in innervated rat skeletal muscle are abolished by $10^{-6} \mathrm{M}$ TTX or $10^{-7} \mathrm{M}$ STX (13). Fig. 1 illustrates the results from a myotube whose action potential was quite sensitive to TTX and STX. We seldom encounter myotubes exhibiting this level of sensitivity. The response in

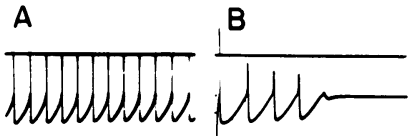

C

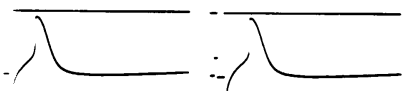

FIG. 2. Electrophysiological conventions as in Fig. 1. A, a myotube which contracted spontaneously and exhibited spontaneous action potentials when impaled. Control Tyrode's. Within $90 \mathrm{sec}$ of perfusing the dish with $1.6 \times 10^{-6} \mathrm{M}$ STX the spontaneous activity was abolished. B, after $10 \mathrm{~min}$ in STX the myotube exhibited the response to current stimuli illustrated here. The first action potential was elicited by current stimuli; the remaining are spontaneous. Note that the first action potential overshoots zero potential (by about $30 \mathrm{mV}$ ). C and D, illustration of the insensitivity of L6 myotubes to $\alpha$-DH-GTX-II. Response in control Tyrode's (C) and after $1 \mathrm{hr}$ in $10^{-5} \mathrm{M} \alpha$-DH-GTX-II (D). See also Table 1.

$\mathrm{Na}^{+}$-free solution is very characteristic and occurs even when the action potential is unaffected by TTX or STX. The response to TTX and STX is highly variable under our stimulating conditions, with fibers showing 5-95\% reduction in the amplitude of the AP in 1.0 to $1.6 \times 10^{-6} \mathrm{M} \mathrm{STX}$ and a $0-40 \%$ reduction in $10^{-5} \mathrm{M}$ TTX. Fig. $2 \mathrm{~A}$ and $\mathrm{B}$ illustrates the response of a myotube which is very resistant to $1.6 \times$ $10^{-6} \mathrm{M}$ STX. This variation exists from cell to cell in the same dish and does not correlate with age of the culture, size or morphology of the myotube, subclone number or number of cell generations away from cloning, batch of fetal calf serum being used, or any other variable that we have been able to identify.

To elucidate the source of this variability, we would have to estimate the percentage reduction in the peak $\mathrm{Na}^{+}$current affected by various concentrations of TTX or STX. This would have to be obtained from voltage clamp experiments, which in this system would be a very difficult technical undertaking.

\section{Sensitivity to veratridine and interaction with TTX and STX}

In an attempt to study further the nature of the voltage-dependent $\mathrm{Na}^{+}$ionophore in L6, we used the plant alkaloid veratridine, which increases the resting $\mathrm{Na}^{+}$permeability of the membrane in a variety of tissues (17). In contrast to the variable response to TTX and STX, the effects of veratridine were consistent.

(i) Short-Term Effects. Veratridine $\left(10^{-4} \mathrm{M}\right)$ within the first 3-10 min of application consistently produces a marked prolongation in the falling phase of the AP (see Fig. 3). Within the first $10 \mathrm{~min}$ there is no consistent reduction in the resting potential. We have not observed veratridine to induce spontaneous or repetitive firing; the cells remain capable of responding to current stimuli with no detectable change in threshold. The after-potential which is masked by the falling phase of the AP (compare Fig. 3B and F) will be described in detail elsewhere; for the present discussion we briefly summarize its properties. (i) The after-potential is a graded, voltage-dependent process and can be elicited by depolarizing current stimuli in control or $\mathrm{Na}^{+}$-free Tyrode's; (ii) the membrane conductance is high in the hyperpolarizing phase and returns to normal in the repolarizing phase; (iii) the amplitude of the after-potential is increased in Tyrode's containing $0.5 \mathrm{mM} \mathrm{KCl}$ and markedly reduced in solutions containing $25-30 \mathrm{mM} \mathrm{KCl}$; and (iv) external $\mathrm{Ca}^{++}$is 


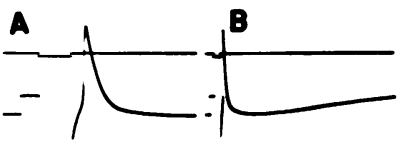

C D
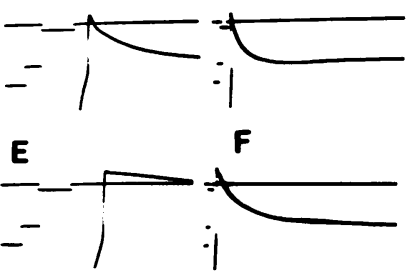

FIG. 3. Electrophysiological conventions as in Fig. 1. Effects of $10^{-4} \mathrm{M}$ veratridine on the action potential. A-F are from the same myotube. $A$ and $B$ illustrate the control action potential at two different time scales. Note the slow hyperpolarizing after-potential. C and $D$, response to current stimuli after $3 \mathrm{~min}$ in $10^{-4} \mathrm{M}$ veratridine. Note the prolongation of the falling phase of the action potential, which masks the hyperpolarizing after-potential in D. E and $F$, response to current stimuli after $10 \mathrm{~min}$ in $10^{-4} \mathrm{M}$ veratridine. The marked prolongation of the falling phase of the action potential completely masks the after-potential. It takes several hundred milliseconds for the potential to return to resting level. Note different time scales in D and F.

not required to elicit the after-potential. On the basis of these observations we conclude that the after-potential is due to the activation of a voltage-dependent $\mathrm{K}^{+}$conductance. The after-potential can be elicited in the presence of $10^{-4} \mathrm{M}$ veratridine by a short depolarizing pulse and its activation kinetics appear unchanged (data not shown). We conclude that veratridine prolongs the AP, presumably by slowing down the process of $\mathrm{Na}^{+}$-current inactivation, a result which is consistent with the observations made in other tissues (17). These effects of veratridine are not prevented by TTX or STX; in fact, the prolongation is seen even when the cell is preincubated in $10^{-5} \mathrm{M}$ TTX or $10^{-6} \mathrm{M} \mathrm{STX}$ and then veratridine $\left(10^{-4} \mathrm{M}\right)$ is added in the presence of TTX or STX.

(ii) Long-Term Effects. After the first $10 \mathrm{~min}$ the resting potential of the cells is observed to decrease (whether the cell is being electrically stimulated or not); by $1 \mathrm{hr}$ the depolarization is maximal to about -5 to $-10 \mathrm{mV}$. As the cell depolarizes it loses the ability to generate an AP as a response to current stimuli and does not generate APs spontaneously.

Because of the difficulty in holding cells for periods of 1 hr or longer, a statistical method was used to examine the veratridine-induced depolarization. The resting potential of a group of cells was recorded in control Tyrode's. The dish was then treated with $10^{-4} \mathrm{M}$ veratridine for $1 \mathrm{hr}$, and the resting potential of another group of cells was measured. It is possible that spuriously low values for the resting potential could be obtained due to properties of the recording electrode. Data were discarded if at the end of the experiment it was not possible to record normal resting potentials in an untreated plate with the same electrode(s).

Table 1 shows the results of three representative experiments indicating the variation observed in different plates and clones. The values are means \pm SEM and the number of observations is in parentheses. Veratridine $\left(10^{-4} \mathrm{M}\right)$ induces a depolarization of the resting membrane potential of about $40 \mathrm{mV}$. There is no overlap in the values for the resting potential before and after veratridine treatment; the difference is statistically highly significant. The depolarization is $\mathrm{Na}^{+}$dependent; if $\mathrm{Na}^{+}$is removed from the external medium no change in the resting potential is seen.

In contrast with the effects on the AP, the effects of veratridine on the resting potential are antagonized by TTX or STX. The depolarizing action of veratridine is largely inhibited when cells are treated for $1 \mathrm{hr}$ in $10^{-4} \mathrm{M}$ veratridine plus $10^{-5} \mathrm{M}$ TTX, although the observed depolarization $(7-11 \mathrm{mV})$ is statistically significant. STX is more potent, at $10^{-6} \mathrm{M}$ causing full inhibition of the depolarizing action of veratridine (Table 1 ).

Significantly, under these conditions the myotubes are capable of generating overshooting APs. After recording the control resting potentials which make up the entries in Table 1 for veratridine plus STX, cells were tested for ability to generate an action potential. About $70 \%$ of the cells tested were responsive to current stimuli. After $1 \mathrm{hr}$ in $10^{-4} \mathrm{M}$ veratridine plus $10^{-6} \mathrm{M}$ STX, cells were examined for their resting potential and ability to generate APs. About $70 \%$ of the cells tested responded with an AP; an example of an AP elicited under these conditions is shown in Fig. 4. Note that the characteristic prolongation of the falling phase induced by veratridine is present.

\section{Insensitivity to a grayanotoxin}

$\alpha$-Dihydro-grayanotoxin-II ( $\alpha$-DH-GTX-II) is a powerful depolarizing agent, which acts by specifically increasing the resting $\mathrm{Na}^{+}$permeability (19). In the squid giant axon it exerts its effect half-maximally at $2.6 \times 10^{-6} \mathrm{M}$ in a few minutes. The effect can be titrated by TTX (19). In contrast to their sensitivity to veratridine, $\mathrm{L} 6$ myotubes are insensitive to $10^{-5} \mathrm{M} \alpha$-DH-GTX-II for up to $1 \mathrm{hr}$ and remain capable of firing APs of unchanged amplitude or shape during this

Table 1. Effects of neurotoxins on resting potential of L6 myotubes (mean millivolts \pm SEM)

\begin{tabular}{cll}
\hline Treatment & \multicolumn{1}{c}{ Control } & After $1 \mathrm{hr}$ \\
\hline $10^{-4} \mathrm{M}$ veratridine & $-43.6 \pm 1.5(12)$ & $-1.5 \pm 0.5(10) P<<0.001$ \\
& $-48.0 \pm 1.3(10)$ & $-5.4 \pm 1.4(10) P<<0.001$ \\
$10^{-4} \mathrm{M}$ veratridine Na ${ }^{+}$-free & $-47.8 \pm 0.8(10)$ & $-7.5 \pm 1.2(10) P<<0.001$ \\
$10^{-4} \mathrm{M}$ veratridine $+10^{-6} \mathrm{M}$ STX & $-50.0 \pm 1.0(12)$ & $-49.4 \pm 1.5(7) P>0.5$ \\
& $-44.4 \pm 1.5(10)$ & $-43.5 \pm 1.2(10) P>0.5$ \\
$10^{-4} \mathrm{M}$ veratridine $+10^{-5} \mathrm{M}$ TTX & $-44.7 \pm 1.0(10)$ & $-43.2 \pm 1.0(10) P>0.3$ \\
$10^{-5} \mathrm{M} \alpha$-DH-GTX-II & $-48.4 \pm 2.6(10)$ & $-39.3 \pm 1.1(10) P<0.001$ \\
\end{tabular}

The number of observations is in parentheses. The statistical analysis used "Student's" unpaired $t$ test. The $P$ values given are the twotailed probabilities in which the values of the $t$ distribution for the appropriate number of degrees of freedom are used. 


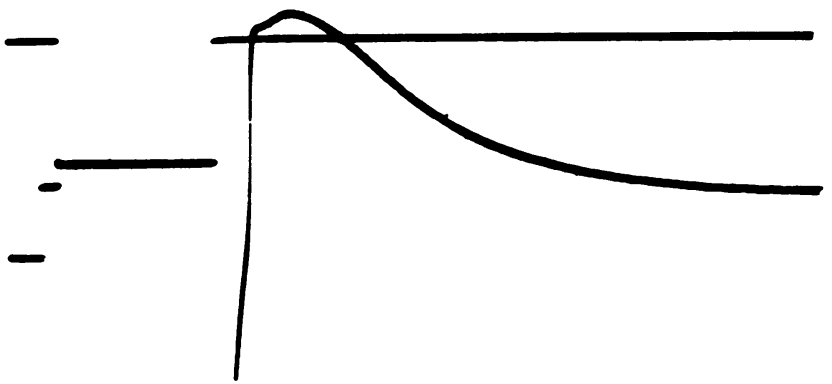

FIG. 4. Electrophysiological conventions as in Fig. 1. Response to current stimuli of a myotube after treatment for $1 \mathrm{hr}$, in $10^{-4} \mathrm{M}$ veratridine plus $10^{-6} \mathrm{M}$ STX. See text for details.

period. Table 1 and Fig. $2 \mathrm{C}$ and $\mathrm{D}$ show the results of representative experiments.

\section{DISCUSSION}

We will discuss our findings within the context of two issues: (i) developmental significance and (ii) implications about the mode and site of action of the pharmacologic agents used in this study.

1. The results presented here provide a pharmacologic characterization of the $\mathrm{Na}^{+}$ionophores present in $\mathrm{L} 6 \mathrm{my}$ otubes. The L6 ionophores respond to the agents tested very differently from the response of innervated skeletal muscle $(13,17)$; the similarity in the properties of L6 ionophores and those present in embryonic (10-12) and denervated skeletal muscle (10-12) suggests that innervation plays a crucial role in the transition from the embryonic to the adult form of the ionophores. L6 myotubes can be successfully innervated in vitro (ref. 15; Land, Gartner, and Podleski, unpublished); thus, it should be possible to study in this system the role of innervation on the change in the properties of the ionophores. The characterization presented here provides the groundwork toward this goal.

A further suggestion on the role of innervation in regulating sensitivity to TTX and depolarizing agents comes from the work of Albuquerque and Warnick (21), who observed that the effects of the depolarizer batrachotoxin were antagonized by TTX in innervated skeletal muscle; during denervation the sensitivity of the muscle to batrachotoxin did not increase, but the ability of TTX to antagonize the effects of batrachotoxin decreased in parallel with the appearance of TTX-resistant APs. Our studies using batrachotoxin on L6 myotubes are in progress.

2. Neurotoxins with known specificity for $\mathrm{Na}^{+}$ionophores provide useful tools for characterizing and monitoring changes in the properties of the ionophores. However, our inferences about the structures of the ionophores will be no more accurate than our knowledge about the mode and site of action of the agents used. The observations that TTX and STX can antagonize the effects of veratridine on the resting potential, but not its effects on the AP (Table 1 and Fig. 4), raise the question of whether the voltage-dependent $\mathrm{Na}^{+}$ionophores are functionally distinct from the ionophores responsible for the resting permeability to $\mathrm{Na}^{+}$. Furthermore, the highly variable effects of TTX and STX on the action potential require some explanation. We discuss these points below.

TTX and STX reduce not only the peak $\mathrm{Na}^{+}$conductance during an AP; TTX (and presumably also STX) also reduces the resting $\mathrm{Na}^{+}$permeability (22-24). We have not observed a consistent hyperpolarization induced by TTX or STX; however, in the course of perfusing the dish with different solutions there is some change in the resting potential of the myotubes. A hyperpolarization of up to $5 \mathrm{mV}$ could go undetected.

Veratridine has been claimed, on the basis of physiological (17) and ${ }^{22} \mathrm{Na}^{+}$uptake experiments (25), to induce a steady-state activation of the voltage-dependent $\mathrm{Na}^{+}$ionophores. In these experiments TTX was shown to antagonize the effects of veratridine, but in view of the effect of TTX on the passive permeability to $\mathrm{Na}^{+}$, the interpretation of these results in terms of the activation of voltage-dependent ionophores is ambiguous.

Our results are readily interpreted in terms of a model which assumes that $(i)$ the voltage-dependent $\mathrm{Na}^{+}$ionophore and the ionophore responsible for the passive permeability to $\mathrm{Na}^{+}$are functionally distinct entities; (ii) TTX and STX have a low and variable affinity for the voltage-dependent $\mathrm{Na}^{+}$ionophore (Figs. 1 and 2); (iii) TTX and STX block the passive $\mathrm{Na}^{+}$ionophore $(22-24)$; (iv) veratridine has the dual effects of $(a)$ slowing the closing of the voltagedependent $\mathrm{Na}^{+}$ionophores which have been opened by current stimuli (Figs. 3 and 4) and (b) steady-state activation of the passive $\mathrm{Na}^{+}$ionophore (Table 1); (v) TTX or STX cannot antagonize the effects of veratridine on the voltage-dependent $\mathrm{Na}^{+}$ionophore (Fig. 4); and (vi) TTX and STX can antagonize the effects of veratridine on the passive $\mathrm{Na}^{+}$ionophore (Table 1). Conclusions similar to these, suggesting heterogeneity in the electrogenic membrane (26), have been reached in studies of the effects of batrachotoxin on cardiac Purkinje fibers (27) and in recent physiological and biochemical work on the grayanotoxins $(19,28,29)$.

However, other alternative models must be seriously considered. By making a number of assumptions about the binding constants of the agents used in this study, our data can be qualitatively explained by a two-state allosteric model which explicitly introduces voltage-dependence of the ionophore but does not assume that a separate ionophore mediates passive $\mathrm{Na}^{+}$permeability (R. E. Gibson, personal communication).

In both the allosteric model and the model that assumes functionally distinct voltage-dependent and passive ionophores, the variable action of TTX and STX on the AP would be the result of differences in the binding constants of the ionophore for TTX and STX. The reason for these differences among myotubes remains obscure.

A third alternative model is that $\mathrm{L} 6$ myotubes have two types of voltage-dependent $\mathrm{Na}^{+}$ionophores, one type sensitive to TTX and STX, and the other type insensitive to these agents. A given myotube would have varying numbers of the two types of ionophores, thus accounting for the variable effects of TTX and STX on the AP. Presumably, veratridine would act on the TTX-sensitive population, and there is a sufficient number of these in all myotubes to produce the observed depolarization due to veratridine, as well as the prolongation of the AP.

We cannot at present exclude any of these three alternatives. We have not used the maximum rise rate of the AP as a measure of peak inward current, and thus attempted to obtain apparent binding constants for TTX and STX for the following reasons. The maximum rise rate will be proportional to the peak inward current only if $(i)$ the peak $\mathrm{Na}^{+}$ current flows before the $\mathrm{K}^{+}$or other ionic currents activate significantly and (ii) if the measurements are made under space clamp conditions, given that in our system APs are, in general, not propagated and the distance from the elec- 
trode(s) to the trigger zone is not known. We have no direct evidence on $(i)$, but $(i i)$ is certainly false in this system where myotubes can extend for distances several times their length constant, exhibit complex branching geometry, be electrotonically coupled and yet appear as separate myotubes, and exhibit the electrogenic heterogeneity mentioned in the introduction. To further linearly relate peak inward current to toxin-ionophore affinity we must further assume that in this system (iii) TTX and STX affect only the peak $\mathrm{Na}^{+}$conductance and none of the kinetic parameters and (iv) the voltage at which the peak current is obtained is constant under toxin-free and toxin-containing conditions. Both (iii) and (iv) are unproven in this system or in any system which exhibits resistance to TTX. Thus, resolution of this question will require further experimental tests, most of them involving the use of voltage-clamp techniques.

The insensitivity of the L6 myotubes to $\alpha$-DH-GTX-II is surprising, and suggests that the molecular receptors for $\alpha$ DH-GTX-II and veratridine are distinct and separable in L6 myotubes, as opposed to the giant axon of the squid. The possibility exists that $\alpha$-DH-GTX-II insensitivity and TTX resistance may be linked, inasmuch as crayfish skeletal muscle fibers and Drosophila salivary gland cells are insensitive to both TTX and $\alpha$-DH-GTX-II (J. G. Starkus and T. Narahashi, personal communication).

We thank Dr. E. Schantz for a generous supply of STX. Dr. T. Narahashi kindly supplied us with $\alpha$-DH-GTX-II and shared unpublished data. We gratefully acknowledge useful conversations with Dr. R. E. Gibson and the superb technical assistance of Mrs. S. Nichols. This work was supported by a NIH-NINDS Research Fellowship to A.S. and NIH, NSF, and Muscular Dystrophy Association of America grants to T.R.P.

1. LeDouarin, N., Renaud, D., Teillet, M. A. \& LeDouarin, G. H. (1975) Proc. Nat. Acad. Sci. USA 72, 728-732.

2. Yaffe, D. (1968) Proc. Nat. Acad. Sci. USA 61, 477-483.

3. Kidokoro, Y. (1973) Nature New Biol. 241, 158-159.

4. Land, B. R., Sastre, A. \& Podleski, T. R. (1973) J. Cell. Physiol. 82, 497-510.
5. Kidokoro, Y. (1975) J. Physiol. 244, 129-143.

6. Steinbach, J. H. (1975) J. Physiol. 247, 393-405.

7. Patrick, J., Heinemann, S. F., Lindstrom, J., Schubert, D. \& Steinbach, J. H. (1972) Proc. Nat. Acad. Sci. USA 69, 2762 2766.

8. Land, B. R., Ravdin, P., Salpeter, M. M. \& Podleski, T. R. (1974) J. Cell Biol. 63, 183a.

9. Axelsson, J. \& Thesleff, S. (1959) J. Physiol. 147, 178-193.

10. Diamond, J. \& Miledi, R. (1962) J. Physiol. 162, 393-408.

11. Marshall, M. W. \& Ward, M. R. (1974) J. Physiol. 236, 413420.

12. Harris, J. B. \& Marshall, M. W. (1973) Nature New Biol. 243, 191-192.

13. Harris, J. B. \& Thesleff, S. (1971) Acta Physiol. Scand. 83, 382-388.

14. Purves, D. \& Sakmann, B. (1974) J. Physiol. 239, 125-153.

15. Kidokoro, Y. \& Heinemann, S. (1974) Nature 252, 593-594.

16. Narahashi, T. (1974) Physiol. Rev. 54, 813-889.

17. Ulbricht, W. (1969) Ergeb. Physiol. Biol. Chem. Exp. Pharmakol. 61, 18-71.

18. Ohta, M., Narahashi, T. \& Keeler, R. F. (1973) J. Pharmacol. Exp. Ther. 184, 143-154.

19. Seyama, I. \& Narahashi, T. (1973) J. Pharmacol. Exp. Ther. 184, 299-307.

20. Schantz, E. J. (1971) in Neuropoisons: Poisons of Animal Origin, ed. Simpson, L. L. (Plenum, New York), Vol. 1, pp. 159168.

21. Albuquerque, E. X. \& Warnick, J. E. (1972) J. Pharmacol. Exp. Ther. 180, 683-697.

22. Baker, P. F., Blaustein, M. P., Keynes, R. D., Manil, J., Shaw, T. I. \& Steinhardt, R. A. (1969) J. Physiol. 200, 459-496.

23. Narahashi, T., Albuquerque, E. X. \& Deguchi, T. (1971) J. Gen. Physiol. 58, 54-70.

24. Freeman, A. R. (1971) Comp. Biochem. Physiol. 40A, 71-82.

25. Catterall, W. A. \& Nirenberg, M. (1973) Proc. Nat. Acad. Sci. USA 70, 3759-3763.

26. Grundfest, H. (1966) Ann. N.Y. Acad. Sci. 137, 901-949.

27. Hogan, P. M. Albuquerque, E. X. (1971) J. Pharmacol. Exp. Ther. 176, 529-537.

28. Narahashi, T. \& Seyama, I. (1974) J. Physiol. 242, 471-487.

29. Soeda, Y., O’Brien, R. D., Yeh, J. Z. \& Narahashi, T. (1975) J. Membr. Biol. 23, 91-101. 